part of its osseous substance is formed from cartilage. Again, if we look at a transverse section of the shaft of a bone, and imagine a line drawn round a lacuna so as to circumscribe it, together with its canaliculi, and thus represent the circumference of the cell in which it is supposed to be formed, it will be obviously seen that the included space is not filled up by concentric strata, nor even by amorphous deposit, but is crossed by numerous Haversian lamellæ, which would also intersect the circumference of the imaginary cell. The intercommunication of the canaliculi of neighbouring lacunæ is another difficulty which has occurred to Professor Kölliker himself; and to obviate this latter objection, he has eked out Henle's hypothesis, by supposing that after the lacuna with its canaliculi have been produced within a cell in the way above described, the latter are subsequently lengthened out and extended through the surrounding hard tissue by absorption. Thus propped up, the hypothesis may meet both objections; but Schwann's explanation being more simple, will probably be found more satisfactory, especially when we keep in mind that the blastemal cells, from which nearly all the lacunæ in a bone must be formed-supposing these arise from cells at all-have never been seen to undergo the partial concentric calcification observed in cartilage-cells, to which so much (as we believe) undue importance has been attached.

We still consider the question of the formation of the canaliculated lacunæ as by no means settled; and with this remark we take leave of the subject, and, for the present, also of Professor Kölliker's most able and elaborate work; in which, copious as it is, the most accomplished anatomist can yet scarce open a page without finding instruction.

\title{
Ant. XII.
}

1. History of a Successful Case of Ovariotomy. By E.W. Dufris, Surgeon. With a Description of the Morbid Anatomy of the Sac. By RoBERT LEE, M.D., F.R.S., \&c. \&c.

2. An Analysis of 162 Cases of Ovariotomy, which have occurred in Great Britain. By Robert Lee, M.D., F.R.S.

(From the 'Medico-Chirurgical Transactions,' Vol. XXXIV. London, 1851.)

The interest which has been recently excited in the profession on the subject of Ovariotomy, has induced us to anticipate a little the notice we are accustomed to bestow on the 'Transactions of the Medico-Chirurgical Society,' for the purpose of bringing under the consideration of our readers at the earliest moment possible, the remarkable statistical paper which Dr. Lee has contributed to the volume that has just appeared. As connected with it also, and as ushering in the valuable series of papers which we shall take the first opportunity of analyzing, we shall now give some account of the paper which stands first in order in the present volume. The operation of Ovariotomy has now been so frequently performed in this country and elsewhere, that we presume a simple record of a successful case would not have found its way into the 'Medico-Chirurgical Transactions,' except as displaying some circumstance of unusual interest or importance; and accordingly it is to the Supplement of Dr. Lee that we 
must look for an explanation of the insertion of Mr. Duffin's paper, as the case itself differs little from many others that are familiar to the profession.

On the 23rd of August, 1850, a woman, 38 years old, applied to $\mathrm{Mr}$. Duffin on account of an ovarian tumour which distended the abdomen to the size that it attains in the last month of pregnancy. The patient was in good health, and was very urgent for the removal of the disease, in consequence of severe neuralgic pains which it occasioned in the right thigh, from pressure on the sciatic nerve, as was afterwards proved. It is not stated whether she had ever borne children. The surgeon in this case quickly made up his mind both as to the nature of the tumour, and what to do with it; for on the fifth day from his first seeing the patient, he opened the abdomen, and fortunately meeting with no adhesions, quickly relieved the sufferer from the burden which had oppressed her for between seven and eight months. Following the plan which, as will be seen hereafter, has been attended with considerable success, he first examined the nature and connexions of the tumour through an incision in the abdominai wall, of sufficient size to admit the forefinger; and there being nothing discovered to contraindicate the removal of the disease, this opening was enlarged to the extent of nearly three inches; and the contents of the sac, amounting to 130 fluid ounces, having been evacuated through a trocar, the cyst was drawn through the aperture. The root of the tumour contained three large arteries and a considerable vein, which were secured by a double ligature passed through its centre, and tied on each side ; another ligature was then passed round the whole neck, and the cyst removed by dividing its attachment, which was about an inch and a half in length. The ligatures were stitched in the wound, with the view of preventing the cut surface from receding into the pelvis and setting up inflammation when it commenced to suppurate; and this contrivance was found to answer its purpose in every way. The wound closed by the first intention, reopened on the ninth day, and on the fifteenth the ligature and slough escaped. In less than three weeks after the performance of this formidable operation, the patient was moving about again, and has since returned to her usual employment.

Dr. Robert Lee carefully dissected the tumour, and has recorded some particulars not generally noticed. The cyst was composed of three layers, -a peritoneal covering, a middle fibrous coat, and a thick membranous sac, in which the fluid had been contained. The peritoneal coat retained the usual characters of that membrane. The middle coat was composed of several layers, to which arteries and nerves, with ganglionic enlargements, were distributed. And the internal coat presented the interesting appearance of being composed, like the Graafian vesicle, of two perfectly distinct membranous layers.

The following paragraph we extract in Dr. Lee's own words, as they probably best explain the peculiarity which he discovered in the formation of this multilocular cyst. It will at once be observed that this account differs from that given by Dr. Hodgkin of the usual development of compound cystoid growths; whilst it accords with the views of Rokitansky :

"Imbedded in the middle coat, near the root, is another and much smaller cyst, with a lining membrane which presents, on the inner surface, precisely the same appearances as those seen on the inner surface of the larger cyst. The lining 
membrane of this smaller cyst is likewise composed of two distinct layers, like that of the larger cyst and the Graafian vesicle, both before and after the escape of the ovum. From the preparation it is seen that a thin stratum of the middle coat is interposed between these two cysts, and that they are independent of each other. But the smaller cyst, though not adherent to the outer surface of the larger, has grown so as to encroach on the cavity of the latter, the lining membrane of which [the] smaller cyst has protruded before it. From this dissection it is obvious that the smaller cyst did not grow from the inner surface of the larger, nor from its outer surface; but that, in the progress of development of the smaller cyst, it pushed before it a portion of the lining membrane of the larger, and thus acquired the layer of reflected membrane from the inner coat of the larger cyst by which it is invested.

"At the base or root of the great cyst in the middle fibrous coat, between the outer surface of the smaller cyst and peritoneum, there is a group of small multilocular cysts, which contained similar fluid, have all the same structure, and bear the same relation to one another, as the two cysts above described. These multilocular cysts have evidently been formed independently of each other; but in the progress of their growth and enlargement, some of them have encroached upon the cavities of those cysts with which they were contiguous, and in the same mechanical manner have acquired reflected portions of their membranes." (p. 8.)

The present race of Obstetricians may fairly claim the distinction of having set the profession by the ears, more frequently and with greater violence than any other class of practitioners. In the instrumental department, the Speculum and the Uterine Sound, and in the operative one, the Cæsarean section and the extraction of diseased Ovaria, have each engaged, on several occasions, the angry attention of the Royal MedicoChirurgical Society. Whether the manner in which these disputes have been conducted, can claim the merit either of contributing to the advance of truth, or of increasing the respectability of our calling, constitutes a serious question, which we shall not, at present, attempt to determine. Those who do not practise midwifery may well be excused, if they suspect a little exaggeration, and a little lack of calm good sense, when they observe the eminent men who are arranged on either side holding diametrically opposite opinions upon the value of particular instruments, the use of which can hardly be so difficult to settle as some disputants would have us to believe. Other departments of the medical profession are not, however, so pure, that we feel justified in holding up any one of them as a pattern for the rest; for it is very certain that jealousy and partizanship are vices not.confined to the champions of the science and practice of obstetrics.

On the present occasion, Dr. Lee has contributed a most valuable addition to the statistics of an operation which interests every class of the profession - the physician and surgeon, equally with the obstetrician. The subject of Ovariotomy has long and painfully engaged the public attention; its results, when successful, being calculated to excite wonder and admiration; whilst the fatal issue must, in many instances, have filled the mind of those who have been admitted behind the scenes, with such feelings of disgust and horror, as the recital of details of barbarity almost -unparalleled in the history of science could not but excite. The question, however, is an urgent one, which admits of no delay in its settlement. Any one of us may be called upon to-morrow to determine for some unhappy female, whether she shall pass the short remainder of her life in 
a condition of great and permanent discomfort, if not of actual pain; or whether the improvement of our art holds out to her a reasonable prospect of relief by the performance of an operation. It is impossible to think, without feelings of the deepest responsibility and compassion, on the number of families, in this country alone, to whom the subject is of the most vital importance, and who are, at this moment, looking to us for some solution to their hopes and fears. A disease which attacks females of all ranks, just at the time when their lives are most valuable, and which, in too many cases, rapidly proceeds to a fatal termination quite unchecked by medicine, is one that naturally claims the most favourable consideration for any plan of treatment which promises certain and complete relief. In such a case, it becomes us to cast aside every vestige of prejudice, or party spirit; to weigh deliberately every fact; to judge charitably, yet not hastily or imperfectly; and to decide only after the most careful deliberation.

It is not, therefore, without anxious thought, that we pronounce an opinion that the Table of Dr. Lee does not, in its present state, furnish us with the means of fully and fairly settling the question of the merits and demerits of ovariotomy.

We admit that the evidence upon which the question is to be decided - whether in Great Britain any more women should be submitted to this operation-is to be found in the detail of cases that have already occurred in this country. The exclusion of continental experience doubtless militates against the positive certainty that we may hereafter attain; but considering the extreme difficulty there has been in getting together a body of facts relating to this country alone, it is not reasonable at present to expect any great addition to our information from foreign sources.

But it has been objected that while we have accounts of all the successful cases, many fatal ones have been kept in the background; and there is much reason to suppose that this humiliating statement is founded in truth. Would that all our brethren counted themselves " debtors to their profession," and that operators especially were impressed with this great truth. Can there be a more flagrant violation of a solemn duty, than the practice of keeping in the background what experience has taught, that may be unfavourable to any peculiar plan of treatment or unwonted operation? What is it when a man knowingly lets his fellows carry away a false impression on such subjects, but to violate every law of truth-to indorse a lie? What moans, what bitter anguish, what unavailing regrets, have not these men to answer for in a world already so full of tears! Will nothing touch their callous mercenary minds - no consideration compel them to a tardy honesty? If insensible to the contempt of their more honourable brethren, do they never think of a yet higher responsibility? Seldom has our profession exhibited a more degrading scene, than on that memorable night at the Medico-Chirurgical Society, when appeal after appeal was made, and made in vain, to those who had experience of ovariotomy, to come forward and boldly speak the truth. The appeal, which was then scarcely responded to, has been but very imperfectly answered since.

We must be cautious, however, not to attribute too much weight to this circumstance. We have 162 - or, as will be seen by and by, 167facts to judge from, upon which we can rely-a much greater body of 
evidence than has been considered sufficient to determine many similar questions. If the operation is to be judged of statistically, figures alone are admissible into our calculations. It will not do to trust to statistics, so long as they support any views to which we happen to have a leaning, and then to throw in a make-weight of impressions and hear-say reports. Such phrases as "I suspect," "I understand," and even "I have reason to know," are very apt to pass for more than they are worth, and to mislead the judgment to an extent that has always been very destructive to the exactitude of medical science. We make these observations preparatory to entering into a minute analysis of Dr. Lee's Table; but before doing so we think it advisable to remind our readers of one or two circumstances important to be had in remembrance, as aids to our judgment.

In the first place it is not uninstructive to observe the vast difference that exists between the earlier and the later operation for the removal of a diseased ovarium.

Contrast the third case in which this operation was performed in this country, by Mr. Lizars, with many of the cases in which the minor operation, as it is called, has since been resorted to.

We quote the account given in Dr. Lee's Table.

"CASE 3.-March 22, 1825. Patient's age 25. Ovarian tumour, seven pounds, adhering to the brim of the pelvis, colon, and abdominal walls, which were partly overcome by dissection, tension, and the handle of the scalpel; incision from sternum to symphisis pubis. Gangrene of the intestine followed." (p. 14.)

For an illustration of the operation by the small incision, we cannot do better than refer to the account we have already given in Mr. Duffin's case.

Now we quote these two cases with no other object than that of inducing those who have very naturally formed strong opinions from what they heard of the earlier examples of ovariotomy, to suspend their judgment until they examine the improvements which experience has effected in its performance. We cannot, indeed, disguise from ourselves the fact that the improved operation is, to a certain extent, only less hazardous than the larger incision. It still retains, of course, that greatest of all its dangers - the wounding the peritoneal cavity; and is, at best, one of the most serious operations in surgery. It is fair, however, to judge of an operation by a reference to the character of the disease for which it is performed. A disease that is sure to end fatally, will justify our incurring a greater hazard for its removal, than one that is an inconvenience only; and it is thus necessary, in limine, to correct the notion that an ovarian tumour belongs to the latter class of cases. It is not correct to assert that in many instances a person may live for years with a dropsy of the ovarium, and may be kept in comparative comfort by being occasionally tapped. In truth, such cases are exceedingly rare. Mr. Safford Lee, in his essay on 'Tumours of the Uterus and its Appendages,' states that more than half the cases ( 63 out of 123) terminated by death in two years, and that 90 out of 123 died within four years. (Op. cit. p. 175.) This agrees very much with the general impression that ovarian disease, like other organic affections, tends to run its course in something like a space of three years-years which emphatically require in this case patience, resig. nation, and sweet temper, to render them even tolerable to the sufferer. 
Tapping-the best means of alleviation in our hands-is also more fatal than is imagined by some, who make too much of the fact that persons are occasionally tapped for the thirtieth or fortieth time. Mr. Southam has collected 20 cases, 14 of which died within nine months of the first tapping -4 surviving it only a few days Of the remaining 6,2 died in eighteen months, while 4 lived for periods varying from four to nearly nine years. Mr. Lee also has recorded the fate of 37 patients, 21 of whom died within four months; 18 of these were only tapped once, and of these again 15 died within the month. (Op. cit. p. 179.) Mr. Lee observes that it is possible that these cases are published because they were fatal, and are considered peculiar, and that they may therefore hardly represent the real mortality of tapping. But on applying to eminent men in London, he found that the general experience of the four whom he consulted very much bore out this result. It is but fair, however, to state, on the other hand, that Mr. Lee's assertions on this point are controverted by Dr. Atlee (Amer. Journ. of Med. Sci., N. S., No. 38) ; who asserts that the numerous inquiries he has made of surgeons in large practice, convince him that death, or even serious symptoms, never result from tapping; that life is usually prolonged, not curtailed, by resorting to it ; while in several cases even permanent recovery has resulted.

This seems the most appropriate place in which to allude to certain cases that were communicated to the Quarterly Meeting of the Bath and Bristol Branch of the Provincial Meaical and Surgical Association in December, 1850 ; in which a modification of the "minor operation" had been resorted to by Mr. Wilson, formerly senior surgeon to the General Hospital at Bristol. The principles upon which Mr. Wilson proceeded in his cases are thus stated by him:

"1st. To make as small an incision as possible.

" 2 nd. To draw out only as much of the cyst as could be extracted readily and without displacement of the other contents of the abdomen.

"3rd. To endeavour to keep the wound always filled with the cyst, so that neither air nor fluid should be admitted into the cavity of the abdomen.

" 4 th. To cut off the cyst, not close to the wound, but from one to two inches beyond it, so that when the portion of cyst has been removed, the cut margins could be carefully examined, and the vessels secured.

" 5 th. To secure each vessel on the cut margin of the cyst, separately with fine silk, and to cut off both ends close, so as to have no ligature hanging from the wound.

"6th. To close the external wound as quickly as possible."

Our limits will not permit us, nor indeed is it our object at this time, to make any comparison between the various methods that have been resorted to for the cure of ovarian disease. We only mention Mr. Wilson's cases as illustrations of our observation, that the operation of ovariotomy has undergone a vital change since it was first proposed and resorted to. Suffice it here to say, that, including two unpublished cases, with the details of which Mr. Wilson has favoured us, he has now attempted this plan in five cases. In three of them he removed large portions of the cyst; two of these patients recovered, and are now in perfect health; the third, a person addicted to habitual but not excessive spirit-drinking, died from peritonitis. In the two other cases to which we have referred, the cyst had contracted too many adhesions to the neighbouring parts, to admit of the 
removal of any portion of it; and Mr. Wilson very properly desisted from the operation. Both these patients rapidly recovered from the exploratory incisions that had been made into their abdomens. The second of these afterwards died from the original disease, which was found to consist of a multilocular cyst with solid malignant deposit.

As all these cases will, doubtless, be published in the 'Transactions of the Provincial Association,' we take leave strongly to recommend them to the notice of our readers.

We would now submit that we are in a position to establish the following propositions, and to determine exactly the questions as to which we should endeavour to obtain information.

1st. There are a few cases of ovarian disease which remain stationary for years, not requiring tapping for the removal of fluid, and consequently not calling for any more serious operation. What is the real proportion of these, and are there any means of forming an accurate prognosis?

2 nd. The large majority of ovarian tumours are uncontrollable by medicine, proceed from bad to worse, and are fatal within a period of between three and four years, passed in great discomfort, often in misery. Can the cases in which this event may be looked for, be certainly distinguished?

3rd. Cases are recorded, in which an operation has been performed for the complete removal of the diseased mass. Does the success that has attended such operations justify us in further resorting to them? In answering this question it must be premised (A) that in some of the cases the ovarian disease has consisted of a cyst or cysts, with or without solid deposit, quite unconnected with any of the surrounding parts, and attached only by its base-in other words, non-adherent; whilst (B) in another class of cases there existed adhesions more or less extensive. In some instances, these adhesions were torn up, and the tumour cut out; in others, after various attempts, the operation had to be abandoned.

4th. Mistakes in diagnosis have occurred; sometimes no tumour being present at all, sometimes disease, which had been mistaken for an ovarian cyst, having existed in the uterus or elsewhere.

5th. On account of the extreme difficulty or impossibility of determining the existence of adhesions, an incision has, in divers instances, been made into the abdominal cavity, through which the nature of the tumour and the extent of its connexions were examined. Does this, which we propose to call "The Exploratory Diagnostic Incision," afford us a legitimate means of verifying our diagnosis? To class such cases with those in which a large opening has been made into the abdomen, and unsuccessful efforts made together to remove the tumour, is not just; nor can they all be included under one head-" cases in which the operation had to be abandoned."

Finally, it must be remembered that in all the fatal cases of every kind, care must be taken to study the cause of death. This, in some instances, has proceeded from circumstances foreign to the operation; in others, from accidents which can easily be avoided in future, or from such as are common to every operation, the most trifling as well as the most serious. How long patients have survived and remained well after the operation of ovariotomy, is another question, upon which the evidence is defective; hardly more so, however, than it is in the case of other operations. 
In almost all the cases of which we have a report, after the lapse of a considerable period, that report is satisfactory; for instance, case 8 , in Dr. Lee's Table, in which the operation was performed in the year 1835, and the patient is still alive, having since given birth to five healthy children. Case 27: Operation, 1843; still living; has had one dead and one living child.-Case 24: Operation, 1844; died two years after, of stricture of the rectum.-Case 26: Operation, 1844; now living.-Case 50: Operation, 1846; now perfectly well. And so likewise in cases $11,12,46,52,59$, $62,63,64,66,69,70,71,72,81,97$, and so on, where the result is stated after the lapse of several years. For a considerable number of cases operated on by Dr. F. Bird, we must refer our readers to the second volume of the 'Lancet' for 1850 ; but the details given are lamentably meagre.

It does not, therefore, seem to us a valid objection to the operation, that we do not know the final issue of the cases. On the contrary, there is reason to believe that the cure is entire and complete, where the patients have survived the immediate effects of the removal of the tumour.

Of the whole number of operations undertaken in this country for the removal of an ovarian tumour, taking into account the cases in which there has been a mistaken diagnosis, and also those cases which have been subjected to the exploratory diagnostic incision, more than a third have died - truly a startling and frightful result.

According to Dr. Lee, the exact number of operations has been 162, of which 61 were fatal; but correcting this table by the addition of Mr. Wilson's 5 cases, the numbers stand thus : operations 167; deaths 62 .

In 8 of these patients, the disease was not ovarian; and two of them died from the effects of what had been done, the third surviving for only a few months. In 3 cases, the disease was a fibrous tumour of the uterus; in one instance, an enlarged mesenteric gland had misled the operator; and in the 4 remaining cases there was no tumour at all.

The results of these 8 cases, numbered as they occur in Dr. Lee's Table, are as follows :

No. 1. Fat.

\section{RECOVERIES.}

4. Fibrous tumour of uterus.

5. Fat and wind.

10. Tumour not found.

106. No tumour.

\section{DEATHS.}

No. 7. Fibrous tumour of uterusremoved.

9. Enlarged gland in mesentery -not removed-died in a few months.

90. Fibrous tumour of uterusremoved.

In 5 of the 8 cases, therefore, where the wound was closed on the discovery of the mistake, the patients recovered.

Non-adherent ovarian tumours were removed in 35 instances, including among them Mr. Wilson's 3 cases, in which he intended to excise only such a portion of the cyst as could easily be drawn out of the wound.

Of these cases, unquestionably the most favourable for the operation of ovariotomy, 10 died, or 1 in $3 \frac{1}{2}$ cases.

The numbers referring to these cases are :

Recoveries - $8,11,13,16,23,26,28$ (health good, but motion of hipjoint interfered with), 44, 52, 54, 82, 93, 97, 98, 104, 109, 110, 111, 115, $116,160,161$. Add to these, two cases by Mr. Wilson. 
Deaths.-19, 20, 49, 85, 94, 95, 113 (tumour 14 lbs.; erroneously stated by Dr. Lee to be 24 lbs.), 124, 156 ; and one case by Mr. Wilson.

Two of the fatal cases-viz., Nos. 19 and 94-may, however, fairly be excepted from our calculations. In No. 19, a favourable one for the operation, the patient died (Mr. Phillips states) from a choleraic form of inflammation of the large intestine-having been purged twenty times the day before the operation, unknown, of course, to him. (Vide 'Medical Gazette,' vol. xxvii. p. 83.) In case 94, operation by Mr. Solly, the ligature slipped, and the patient died from secondary hæmorrhage. (Vide 'Medical Gazette,' vol. xxxviii.) Such a result can manifestly be avoided in future.

Our mortality is therefore reduced to 8 cases out of 35 . Now, surprising as the statement may be, this cannot be considered as an excessive mortality, when compared with that of other capital operations. Many more patients die after a serious operation, than most persons are aware of. We are all disposed to picture the hazards of an operation from the results of individual experience, than which nothing can be more fallacious. If we estimated the perils of lithotomy from its results in the hands of Frère Jacques, or Mr. Martineau, we should involve ourselves in great errors ; and as an illustration of the variation of individual experience at different times, we may mention that a distinguished surgeon of our acquaintance operated successfully for hernia forty consecutive times in private; but coming to operate in an hospital, he lost a great proportion of his cases. In Paris, it is said that every second hernia patient dies; and this statement would not greatly exaggerate the unfavourable experience of English hospitals. Malgaigne's statistics of amputations are well known. Calculating the results in 852 cases, he showed that in the whole number 2 out of every 5 died ; while in the case of the removal of the lower extremities alone, the mortality was even higher, amounting to upwards of a half. It would be easy to prove the same thing from other statistics.

The next class of cases we shall notice includes those in which the tumour was removed in spite of the existence of adhesions; and here we meet with facts that make us blush for our profession. We are cognizant of 35 such cases, and of these, 15, or more nearly a half than a third, perished from the direct effects of the operation. The details of some of these cases are distressing in the extreme. According to Dr. Lee's Table they stand thus :

Recoveries.-Cases 24, 35, 36, 38, 42, 45, 46, 53, 55, 57, 81, 89, 96, $99,117,120,121,122,126,157$.

Deaths.-Cases 3, 7 (already referred to as a fibrous tumour of uterus), $21,22,39,47$ (tumour free from peritoneal attachments, but adherent to Fallopian tubes and uterus), 48, 56, 83, 90 (already quoted as fibrous tumour of uterus), 100, 107, 108, 159, 162.

As specimens of some of these operations take the following :

Case 48.-Both ovaries and uterus were removed, converting the vagina into a cul-de-sac.

Case 108.-Long incision; extensive and strong adhesions, which were violently torn up. A personal friend, who was present at the operation, communicated all the details to Dr. Lee. Death speedily followed. (Unpublished.) 
It is worthy of remark, that in one of the fatal cases-viz. No. 83, as well as in No. 158, included in a subsequent table-the adhesions were of such a character as not to be discovered until the operation had proceeded a considerable length; in this, therefore, the exploratory incision would not have answered its purpose. The operations in this class speak for themselves, and no comments can make them appear more outrageous than do, in some instances, the simple details. It will be sufficient to refer to a single instance which has lately been brought prominently before the public eye - the case operated on by Mr. Baker, at the Birmingham General Hospital, and standing last in Dr. Lee's Table.

The rule may be laid down, that whenever we discover adhesions, except such as are of the most trifling character, the operation must be forthwith abandoned.

Our next table will include the cases in which, on the discovery of adhesions, the operators proceeded no farther in their attempts to remove the tumour; those, also, in which they were obliged to content themselves with the partial removal of the tumour, together with all the known cases of the simple preliminary diagnostic incision.

From Dr. Lee's data we gather, that under this head there were 17 deaths and 43 recoveries; but adding the two cases communicated to us by Mr. Wilson, and another case of the late Mr. Aston Key, mentioned in the report of Mr. Arnott's fatal case in the 'Pathological Transactions' for 1848 , the number of recoveries is increased to 46 , thus making one death in rather more than two and a half cases. The particulars are as follow :

Recoveries.-Cases 1 (already mentioned as no ovarian tumour), 2,4 and 5 (no ovarian disease), 6, 10 (no ovarian disease), 14, 25, 29, 30, 31 (recovered from the operation, but died five weeks after, probably from fatty disease of the heart), 32, 33, 41, 43, 51, 75, 76, 77, 78, 79, 92, 103, 106 (already quoted as no ovarian disease), 112, 114, 119, 129, 130, 131, 133, 134, 135, 136, 137, 138, 139, 140 (died from a subsequent tapping), $142,143,144,145,155$.

We have not hesitated to include under the head recoveries, in this class, cases 137,138 , and 139 ; although, according to Dr. Lee, the result of the first is not stated, and of the two others unknown; for the operator (Dr. Bird) mentions that all these patients were tapped many times afterwards, the inference from which is obvious.

Deaths.-Cases 9 (already referred to as no tumour), 17, 18, 27, 34, 37, $58,80,84,88,101,102,105,128,132$ (lived six weeks), 141, 158.

An important distinction is to be drawn between those cases in which the exploratory incision was employed with the object of discovering adhesions, and those in which every effort was made to remove the tumour, the operation being desisted from only whet: this was found to be impossible. Surely these two cases are not to be classed together.

"Mrs. P—. Married in 1841; never pregnant. January, 1844, first perceived enlargement of the abdomen. In 1846 had strong pressure applied to the abdomen, after being tapped by Mr. J. Brown. A second tapping; the operation of ovariotomy undertaken by Dr. F. Bird, 6th January, 1848; present, Dr. Rigby, Mr. Holt, two assistants, and Dr. Hogg, who has communicated these details to Dr. Lee. "An incision of two inches was made in the linea alba, midway between the umbilicus and pubes, and twenty pints of liquid were drawn off by a large canula; the opening was then fairly made into the cavity of the abdomen, and the 
solid tumour seized by forceps; the size, however, of the tumour was such, that the opening was of necessity extended to ten inches before it could be drawn forth; tumour then found adhering strongly behind the small intestines, and, in fact, to all the abdominal viscera. Dr. F. Bird attempted to separate it from them, by conveying his hand behind it, and, to a certain extent, succeeded in so doing; but on the tumour advancing through the opening, it brought the colon with it, rather before it, which was so firmly adhering that it defied all attempts at separation, even with the handle of the scalpel; the removal being impossible, it was replaced in the abdomen, and the external opening sewed up. The operation occupied an hour and ten minutes, during the whole of which time she was kept under the influence of chloroform. The unfortunate patient, on recovering herself from the effects of the chloroform, stated that she had heard all that was said, but suffered very little. She expired twenty-eight hours after.' (Unpublished.)"' (p. 30.)

\section{And the following:}

" An incision first made of one inch, the finger introduced, and no adhesion felt; opening extended to three inches; the sac tapped; a second cyst detected and tapped, both cysts firmly adhering. Operation could not be completed. (Middlesex Hospital-Pathological Transactions.)" (p. 25.)

With reference to the causes of death also, it should be remarked, that case 9 , where there was no tumour, recovered from the operation, and died a few months after, from the original disease. It is therefore now fairly included in the list of recoveries from the exploratory incision. So case 141 died next day, from the bursting of a large hepatic abscess.

Considering it, therefore, of great moment to ascertain the results of the exploratory incision, beyond which the operation did not proceed, we arrive at the following:

It was employed in cases $14,30,34,76,77,78,79,80,103,129,130$, $132,133,134,135,136,137,138,139,140,141$ (already referred to as hepatic abscess), 142, 143, 144, 145, and in two cases by Mr. Wilson and one by Mr. Key. Out of these 28 cases 4 died, or one in $6 \frac{1}{2}$; but it is to be remembered, that, of the fatal cases, No. 132 lived six weeks, and No. 141 died from the bursting of an hepatic alsscess; so that in only two cases, or 1 in 14, could the death be fairly attributed to the operation. We wish we had the means of making this table more complete; at present it speaks favourably of the result of the "exploratory diagnostic incision." Dr. Bird, indeed, stated, at the celebrated discussion in the Medico-Chirurgical Society, that he himself had employed it in between thirty and forty instances. We need hardly say this assertion is not borne out by the tables he has since published.

There yet remain 35 of Dr. Lee's cases, which, with all our efforts to obtain their details, we have been unable to classify. In these there were 15 deaths.

The task we proposed to ourselves is now nearly accomplished; it remains to draw such conclusions as will guide us in our practice, and may, we would fain hope, prove useful to others also. We do not by any means suppose that our statements are entirely free from error; they must be taken only as approximations to the truth, but they are as near correctness as care and honest intentions can make them. In every instance in which we could do so, we have referred to the original sources from whic' Dr. Lee's Table has been constructed; but as a considerable number of $h$. 
cases are unpublished and communicated privately to him, many of them rest upon his own authority. In the course of our investigation we have been more inconvenienced than we dare say Dr. Lee will believe, by a little carelessness on his part in giving his references.

Thus, case 82 is not in the "Transactions of the Provincial Medical and Surgical Association,' but in the 'Provincial Medical and Surgical Journal for 1845,' and 20 is in the 'New Series of Guy's Hospital Reports.' But these and other such defects may well be excused, in our gratitude for the substantial good which Dr. Lee has conferred upon the profession by the publication of his paper.

The impression, then, which the attentive consideration of the subject has left upon our minds is to the following effect :

1st. That in any case in which it is considered advisable to remove an ovarian tumour, it is justifiable to make a small preliminary incision into the abdomen, for the purpose of determining whether the tumour be adherent or not.

2 nd. If the tumour be adherent, the incision is to be immediately closed entirely, or to such an extent as merely to leave an aperture the size of that made by an ordinary trocar, and we may then expect that this operation will not, on the average, be followed by much more fatal results than common tapping.

3rd. That where the tumour consists of a simple cyst or cysts, with but small solid deposit, it may be extirpated with as good a chance of success as attends the performance of the more serious surgical operations, and with the further prospect of the cure remaining permanent.

4th. The existence of much solid deposit, or of extensive adhesions, absolutely forbids the operation, which should be brought to a termination immediately upon the discovery of either.

Finally, we may add our belief, that the plan proposed by Mr. Wilson, of tying each bleeding vessel separately, so as to dispense with the ligature round the pedicle, is an important improvement; and that, if experience should show that it is sufficient for the cure of the disease to remove only a part of the cyst, the operation will be rendered considerably more hopeful.

We cannot bring our notice of this subject to a conclusion, without again expressing our deep regret that it should have been discussed with so much of acrimony and party-spirit, and that the acknowledged heads of the surgical and obstetric departments of our profession should have left the operative treatment of ovarian disease in the hands of a class of men, who have taken it up chiefly with the view of gaining for themselves notoriety with the profession and the public,-and who, by their unscrupulousness in the performance of ovariotomy at all hazards, and by their want of openness in the publication of their results, have greatly contributed to prevent the real merits of this plan of treatment from being duly appreciated. We trust that the operation will not long remain under the stigma which at a present attaches to it; but that experienced and intelligent surgeons, like 1. Mr. Wilson of Bristol, will at any rate take it upon trial, and endeavour Dr: o devise means for the diminution of its fatality, and for that improvement the $?$ the preliminary diagnosis, which is one of the most important conditions canv, its legitimate success. 